\title{
MUDANÇAS NA PAISAGEM DA BACIA HIDROGRÁFICA DO CÓRREGO TAMANDUÁ, EM IPORÁ, GOIÁS
}

\author{
Alexandre Luiz Gomes* \\ Tiago Batista Mendonça* \\ Jefferson Eduardo Silveira Miranda**
}

RESUMO: O objetivo desse estudo foi analisar as mudanças na paisagem da bacia hidrográfica do córrego Tamanduá, localizada no município de Iporá, em Goiás. Para isso foram analisadas imagens dos satélites Landsat 5 e 8, para classificar a paisagem em três anos: 1996, 2006 e 2016. Os resultados revelaram avanço da área urbana e redução da vegetação, com diminuição dos fragmentos de vegetação nativa. $\mathrm{O}$ crescimento urbano da cidade de Iporá gerou perda de habitat, através do desmatamento para realizar loteamentos e construção de residências. Com isso há evidente perda de vegetação causada pelo processo de urbanização.

PALAVRAS-CHAVE: Cerrado; Ecologia de paisagem; Fragmentação da paisagem.

\section{LANDSCAPE CHANGES IN THE HYDROGRAPHIC BASIN OF THE STREAM TAMANDUÁ, IPORÁ GO BRAZIL}

ABSTRACT: Current study analyzes landscape changes in the hydrographic basin of the stream Tamanduá in Iporá GO Brazil. Images by satellites Landsat 5 and 8 were observed to classify the landscape during 1996, 2006 and 2016. Results reveal progress in the urban area and a reduction of vegetation, with a decrease in native vegetation fragments. Iporã 's urban growth generated loss of habitat due to deforestation for the construction of housing estates. The urbanization process has caused evident loss of vegetation.

KEY WORDS: Savannah; Landscape ecology; Fragmentation of landscape.

\footnotetext{
"Técnico em Gestão Ambiental pela Faculdade de Iporá - FAI, Iporá, Goiás, Brasil.

** Mestre em Ecologia e Conservação. Docente pela Faculdade de Iporá - FAI, Iporá, Goiás. Discente do Programa de pós-graduação lato sensu em Saneamento e Saúde Ambiental, Universidade Federal de Goiás - UFG, Goiânia, Goiás, Brasil. E-mail: jefferson.jesm@gmail.com
} 


\section{INTRODUÇÃO}

Bacias hidrográficas são definidas como "[...] o conjunto das áreas com declividade no sentido de determinada seção transversal de um curso d'água, medidas as áreas em projeção horizontal" (GARCEZ; ALVAREZ, 1988). Esse conceito facilitou o desenvolvimento da gestão ambiental, de modo que as bacias hidrográficas se tornaram unidades básicas no planejamento regional (ROSS; DEL PRETTE, 1998) e passaram a ser cada vez mais destacadas como unidades fundamentais de gestão da paisagem na área de planejamento ambiental (PIRES; SANTOS; DEL PRETTE, 2002; TEODORO et al., 2007). Atualmente as bacias hidrográficas são essenciais para a Gestão de Recursos Hídricos brasileiros, instituído pela Política Nacional de Recursos Hídricos, que tem esse conceito como base da proposta de gestão (AZEVEDO; BARBOSA, 2011).

Os planos de gerenciamento de recursos hídricos podem ser definidos, em menor escala, pelos comitês de bacia hidrográfica, permitindo melhor compreensão da relação entre o uso da água e a qualidade pretendida (PORTO; PORTO, 2008). Por isso, ao direcionar para o planejamento de recursos naturais, o conceito de bacia hidrográfica vai além de aspectos hidrológicos, envolvendo estruturas biofísicas e as mudanças de uso e ocupação da terra (PIRES; SANTOS; DEL PRETTE, 2002), dado que a integração dos diversos aspectos que interferem no uso dos recursos hídricos deve ser questão central na gestão dos mesmos (PORTO; PORTO, 2008).

Nesse sentido é importante dar atenção ao Cerrado, pois o bioma abriga nascentes de seis das oito grandes bacias hidrográficas do Brasil, aspecto que faz a região ser de grande importância para a recarga hídrica do país (LIMA; SILVA, 2005). Porém, a região sofre com ações antrópicas, principalmente com atividades agrárias e implantação de tecnologias energéticas (AB'SABER, 2003). Além disso, há problemas como as queimadas, invasões biológicas e fragmentação de habitat (PIVELLO, 2005).

Goiás está situado inteiramente no Cerrado e também sofre com a intensa pressão antrópica (SAWYER, 2007), por isso é uma área de grande importância para o uso consciente dos recursos hídricos (LIMA; SILVA, 2005). Dentro deste contexto se insere o objeto de estudo desse trabalho, a bacia hidrográfica do córrego Tamanduá, componente da bacia hidrográfica do rio Araguaia. A área ainda não 
possui um comitê formado e, apesar dos estudos relacionados às questões climáticas e morfológicas, ainda não se sabe sobre a dinâmica da paisagem nos últimos anos. Por isso, o objetivo desse trabalho foi estudar as mudanças na paisagem da bacia hidrográfica do córrego Tamanduá, em Iporá, Goiás.

\section{MATERIAL E MÉTODOS}

\section{1 ÁREA DE ESTUDO}

A bacia hidrográfica do Córrego Tamanduá (BT) localiza-se no município de Iporá, Goiás (Figura 1). A região é caracterizada como Aw, segundo classificação climática de Köppen (SILVA; ASSAD; EVANGELISTA, 2008; ALVARES et al., 2013), com clima tropical e duas estações bem definidas no decorrer do ano, um verão úmido e inverno seco (GOIÁS, 2006). A área da bacia é de aproximadamente $30 \mathrm{~km}^{2}$ com formato retangular e o canal principal de $3^{\mathrm{a}}$ ordem (SANTOS; SOUSA, 2013). O principal afluente da BT, o córrego Tamanduá, atravessa a cidade de Iporá e, por isso, é utilizado para o despejo de esgoto.

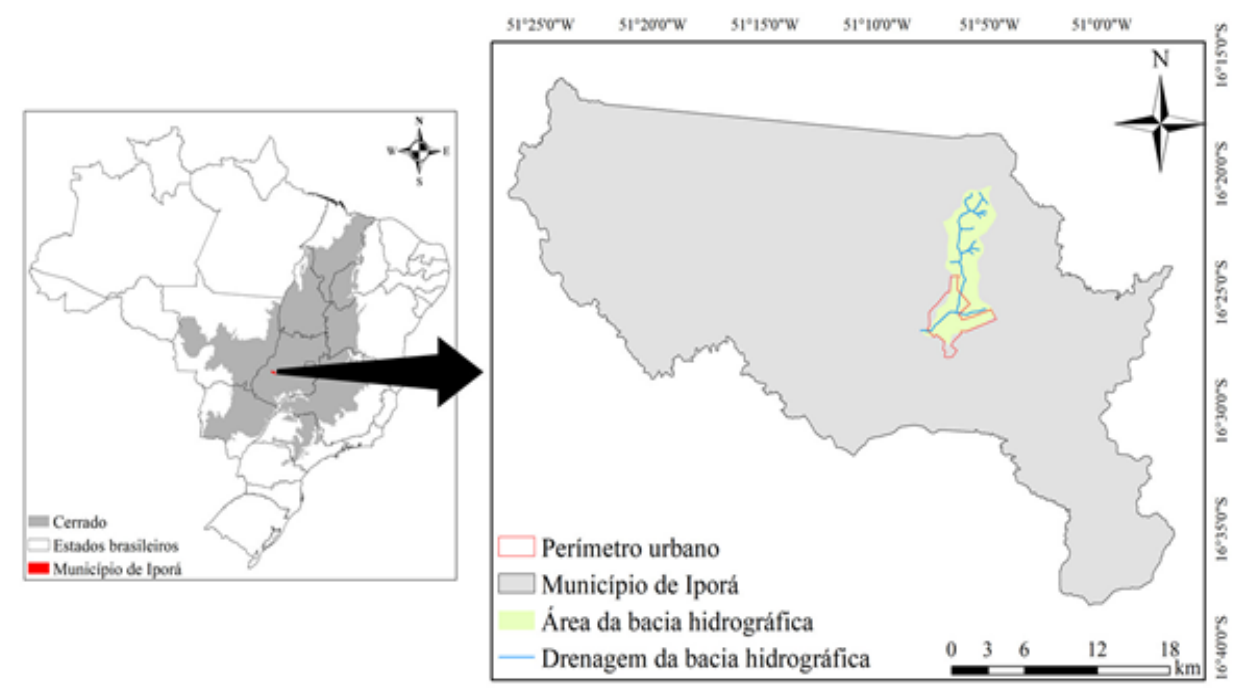

Figura 1. Localização da bacia hidrográfica do Córrego Tamanduá, no município de Iporá, Goiás, Brasil 


\subsection{METODOLOGIA}

Houve a aquisição das imagens do satélite Landsat 5, para trabalhar com os anos de 1996 e 2006, e Landsat 8 para o ano de 2016. As imagens foram obtidas gratuitamente através do site do United States Geological Survey (USGS). Todas as cenas pertenciam ao período de seca, para facilitar a detecção de vegetação natural.

O software ArcGIS 10.5 foi utilizado para trabalhar com as imagens. Primeiro realizou-se a composição das bandas para trabalhar com infravermelho e assim identificar melhor a vegetação natural. Em seguida foi feita a classificação supervisionada da área por meio da ferramenta Maximum Likelibood, com a paisagem dividida em três classes: agropecuária, área urbana e vegetação. Agropecuária corresponde às áreas de pastagem e agricultura, área urbana se refere à cidade e áreas de loteamento, e a vegetação são as áreas de vegetação natural. Para validar a classificação houve visitas no local e conversa com moradores, com o intuito de conhecer e confirmar informações sobre o uso do solo.

Para calcular as métricas da paisagem utilizou o software FRAGSTATS ${ }^{\mathrm{TM}} 4$ (MCGARIGAL; CUSHMAN; ENE, 2012). As métricas (Tabela 1) foram escolhidas de modo que possibilitasse analisar a conectividade da paisagem e perda de vegetação da BT.

Tabela 1. Métricas da paisagem utilizadas. Descrição de acordo com o manual do software FRAGSTATS $^{\text {TM }} 4$

\begin{tabular}{|l|l|l|l|}
\hline Métrica & Nome & Descrição & Unidade de medida \\
\hline SHAPE & Índice de forma & $\begin{array}{l}\text { Maior ou igual a 1. Será igual a 1 } \\
\text { quando o fragmento for quadrado e } \\
\text { aumenta sem limite conforme o frag- } \\
\text { mento se torna irregular. }\end{array}$ & - \\
\hline CICLE & $\begin{array}{l}\text { Relação da } \\
\text { circunferência } \\
\text { com forma } \\
\text { circular }\end{array}$ & $\begin{array}{l}\text { Se aproxima de 0 para manchas circu- } \\
\text { lares e se aproxima de 1 para manchas } \\
\text { alongadas e lineares. }\end{array}$ & - \\
\hline CONTIG & $\begin{array}{l}\text { Índice de } \\
\text { contiguidade }\end{array}$ & $\begin{array}{l}\text { É 0 para fragmentos de um pixel e au- } \\
\text { menta até 1 junto com o aumento da } \\
\text { conectividade. }\end{array}$ & \\
\hline
\end{tabular}


(Conclusão)

\begin{tabular}{|l|l|l|c|}
\hline Métrica & Nome & Descrição & Unidade de medida \\
\hline CA & Área total & $\begin{array}{l}\text { Área total que a classe ocupa na paisa- } \\
\text { gem. Será 100\% quando houver uma } \\
\text { única classe. }\end{array}$ & Hectares (ha) \\
\hline PLAND & $\begin{array}{l}\text { Porcentagem } \\
\text { da paisagem }\end{array}$ & Tamanho da classe em porcentagem. & Porcentagem (\%) \\
\hline LPI & $\begin{array}{l}\text { Índice de maior } \\
\text { fragmento }\end{array}$ & $\begin{array}{l}\text { Porcentagem da área ocupada pelo } \\
\text { maior fragmento. }\end{array}$ & Porcentagem (\%) \\
\hline NP & $\begin{array}{l}\text { Número de } \\
\text { fragmentos }\end{array}$ & $\begin{array}{l}\text { Quantidade de fragmentos na paisa- } \\
\text { gem. }\end{array}$ & \\
\hline AI & $\begin{array}{l}\text { Igual a 0 quando não fragmentos } \\
\text { agregace de } \\
\text { táximos da mesma classe e aumen- } \\
\text { ta medida que a paisagem se torna } \\
\text { mais agregada, é igual a 100 quando } \\
\text { a paisagem é composta por um só } \\
\text { fragmento. }\end{array}$ & Porcentagem (\%) \\
\hline PAFRAC & $\begin{array}{l}\text { Dimensão frac- } \\
\text { tal da relação } \\
\text { perímetro-área }\end{array}$ & $\begin{array}{l}\text { Iguala a 1 para fragmentos com pe- } \\
\text { rímetros de formato muito simples, } \\
\text { como quadrados, e se aproxima de 2 } \\
\text { para perímetros de forma complexa. }\end{array}$ & \\
\hline
\end{tabular}

Fonte: Mcgarigal, Cushman e Ene (2012).

\section{RESULTADOS E DISCUSSÃO}

De 1996 para 2006 houve aumento do número de fragmentos e diminuição na porcentagem da cobertura vegetal e agropecuária (Gráfico 1). No mesmo período a urbanização teve aumento na porcentagem ocupada na área da BT. De 2006 para 2016 ocorreu queda no número de fragmentos (Tabela 2), enquanto a urbanização continuou em expansão.

Os valores de AI indicam uma diminuição da agregação dos fragmentos de vegetação ao longo dos vinte anos. O maior fragmento da bacia hidrográfica reduziu o tamanho, como indica LPI. Em todos os três anos analisados, PAFRAC está com valor inferior a 1,5, que indica a presença de fragmentos simples (Tabela 2). 
1996

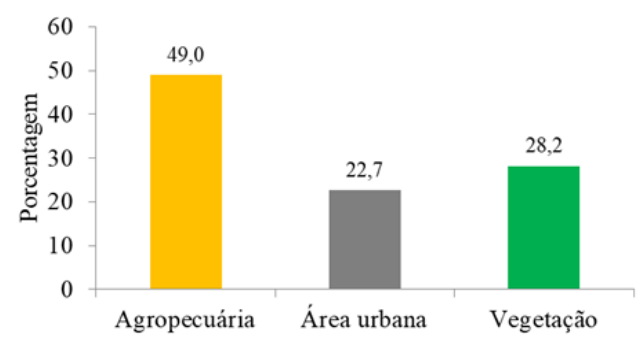

2006

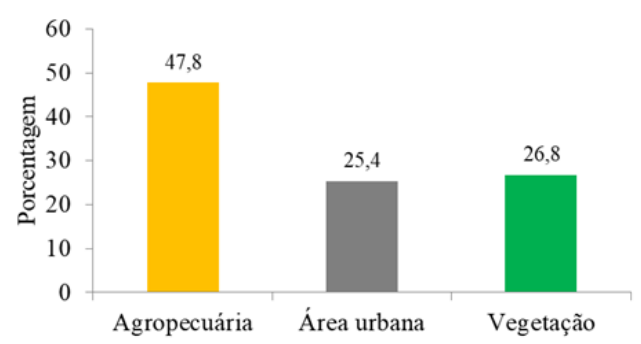

2016

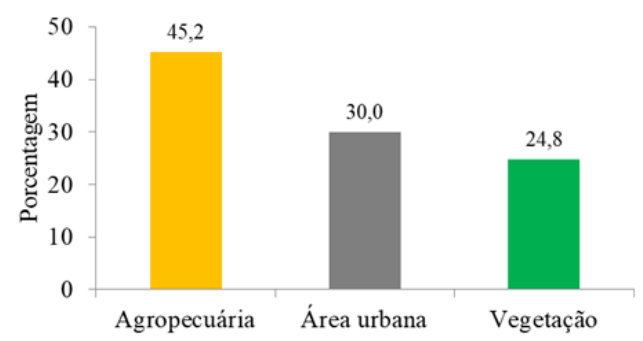

Gráfico 1. Caracterização da paisagem na bacia hidrográfica do Córrego Tamanduá, no município de Iporá, Goiás, Brasil

Tabela 2. Métricas da paisagem da bacia hidrográfica do Córrego Tamanduá, no município de Iporá, Goiás, Brasil. Número de fragmentos (NP). Índice de agregação (AI). Tamanho do maior fragmento de vegetação (LPI). Dimensão fractal perímetro-área (PAFRAC)

\begin{tabular}{lccc}
\hline Métrica (unidade de medida) & 1996 & 2006 & 2016 \\
\hline NP (unidades) & 42 & 49 & 33 \\
AI (\%) & 92,1 & 91,2 & 91,1 \\
LPI (\%) & 22,8 & 18,8 & 16,2 \\
PAFRAC (-) & 1,32 & 1,30 & 1,33 \\
\hline
\end{tabular}


A métrica SHAPE para os fragmentos confirma o que foi observado em PAFRAC: os fragmentos tendem ao formato simples nos três anos analisados. É provável que a maioria acompanhe os corpos d'água dentro da bacia hidrográfica, uma vez que, de acordo com CICLE, a maioria não tem formato circular e sim alongado. Além disso, a bacia apresentou nos três anos grande quantidade de fragmentos bem conectados, de acordo com os valores de CONTIG (Gráfico 2).

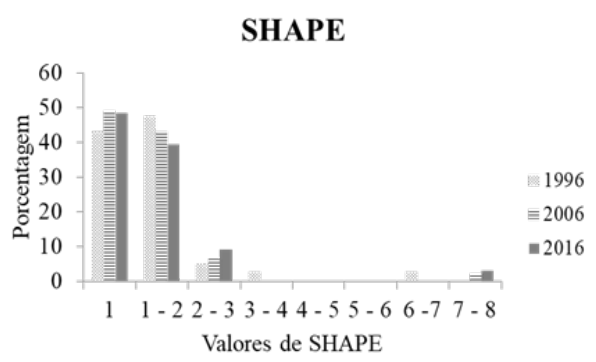

CICLE
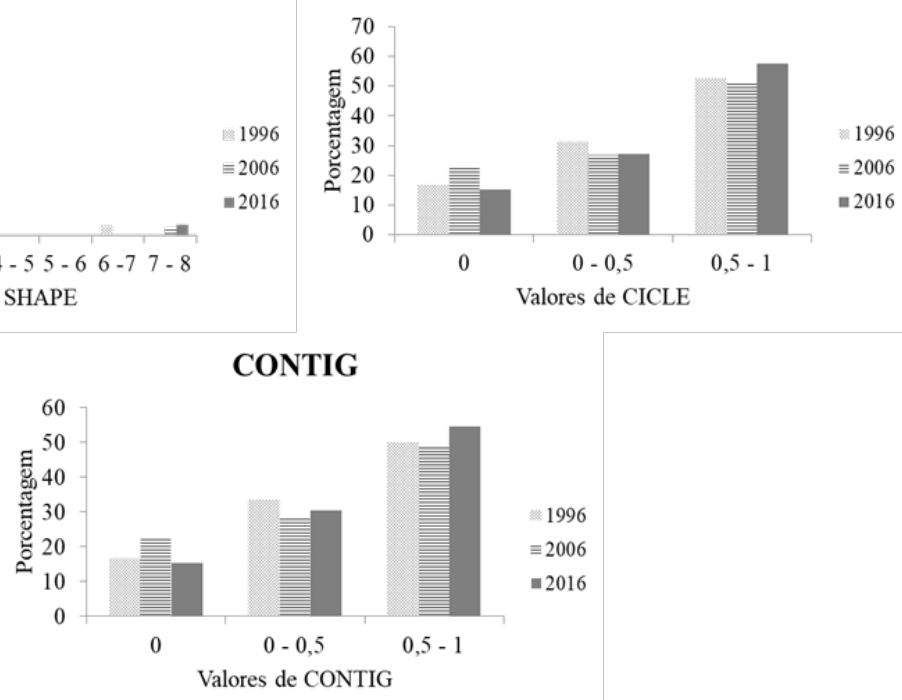

Gráfico 2. Resultados das métricas em nível de fragmento, na bacia hidrográfica do Córrego Tamanduá, no município de Iporá, Goiás, Brasil. SHAPE (índice da relação perímetro-área). CICLE (relação da circunferência). CONTIG (índice de contiguidade).

A redução de fragmentos entre 1996 e 2016 acompanha o avanço de áreas antrópicas, de modo que as áreas urbanas avançam na paisagem enquanto os fragmentos de vegetação desaparecem. O resultado deste estudo se assemelha com outros trabalhos (CHAVES; SANTOS, 2009; COELHO et al., 2014; ETTO et al., 2013), em que há perda de vegetação com o decorrer do tempo (Figura 4). Essa perda de habitat natural tem implicações negativas para biodiversidade (FAHRIG, 2003), tendo em vista que existe uma amostra empobrecida da diversidade original das biotas nas paisagens dominadas pela ação antrópica (TABARELLI; GASCON, 2005). Por isso a 
substituição da vegetação nativa por áreas urbana e agropecuária é prejudicial para a BT. Porém, é um processo difícil de contornar, tendo em vista o claro crescimento populacional que reflete no tamanho da cidade.

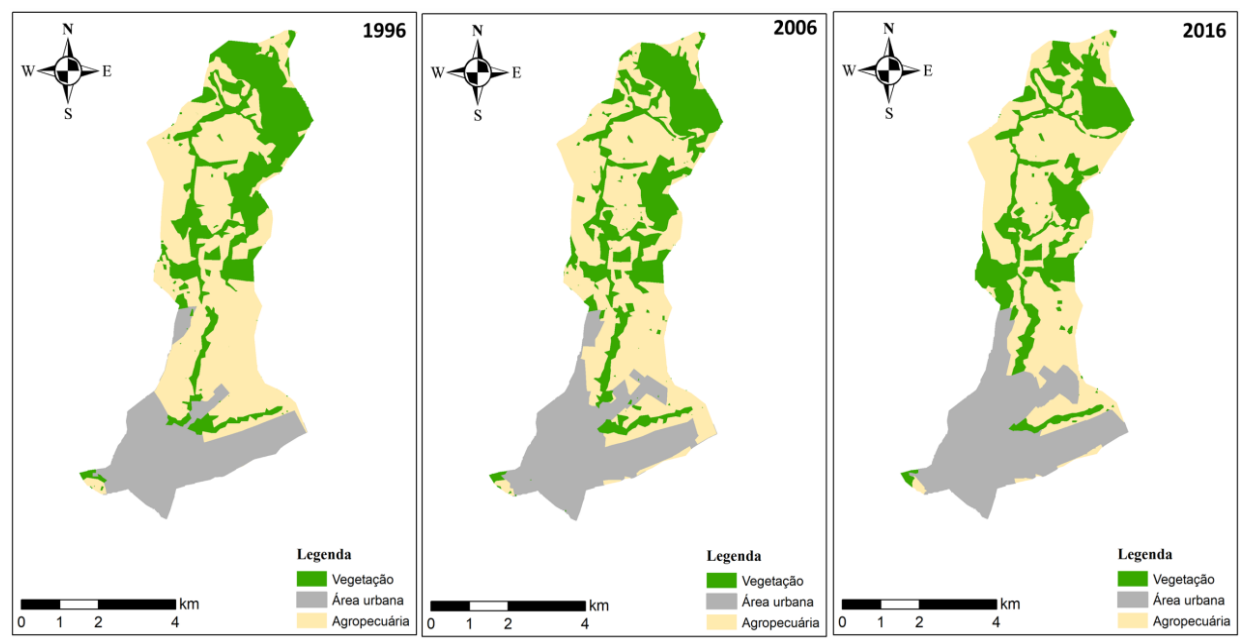

Figura 4. Representação da paisagem na bacia hidrográfica do Córrego Tamanduá, em Iporá, Goiás, Brasil

A ação antrópica destrói o ambiente natural e provoca a fragmentação de habitats, que tem diversos efeitos na biodiversidade (PRIMACK; RODRIGUES, 2001; BRASIL, 2003). O efeito mais óbvio do processo de fragmentação é a remoção do habitat, que modifica o padrão espacial e afeta a biodiversidade (FAHRIG, 2003). Nesse sentido, o gerenciamento das áreas remanescentes é um processo necessário para minimizar possíveis perdas futuras de espécies (SAUNDERS; HOBBS; MARGULES, 1991).

Como a maioria dos fragmentos é de formato simples e alongado, eles acompanham os corpos d'agua (conforme é observado na Figura 4). Apesar da grande perda de vegetação, que pode ser observada na porcentagem de vegetação dentro da bacia e no declínio do número de fragmentos, o pouco que resta de fragmentos ainda está bem conectado, como revela as métricas CONTIG e AI. Mesmo com degradação contínua no decorrer do tempo a conectividade se mantém alta pelo fato da BT ser estreita e ocupar uma área pequena. No entanto, fragmentos 
alongados podem não ser eficientes o suficiente para a conservação de espécies, pois têm maior extensão de bordas e por isso a paisagem regional deve ser manejada (PRIMACK; RODRIGUES, 2001).

Ainda assim, há remanescentes florestais de mata de galeria e ciliar, que é importante conservar para manutenção da qualidade da água. A presença desse tipo de vegetação auxilia na proteção dos recursos hídricos (DONADIO; GALBIATTI; PAULA, 2005) e contribui para melhor qualidade da água (MARMONTEL; RODRIGUES, 2015). Geralmente a má qualidade da água está associada às áreas de uso e ocupação irregulares das áreas de preservação permanente, em que houve a substituição da vegetação original (PEREIRA et al., 2016).

O Córrego Tamanduá corta a cidade e por isso sofre com o despejo de esgoto. Esse tipo de ação acaba prejudicando a qualidade da água, como demonstrado por Cordeiro et al. (2016). Esses autores encontraram resultados que indicam a maior presença de patógenos em locais que há presença de efluente doméstico. Assim, com o aumento da área urbana, que está intensificando nos últimos vinte anos na região de estudo, pode-se esperar menor qualidade da água. Souza e Gastaldini (2014) encontraram relação que corrobora com essa hipótese, indicando que bacias hidrográficas com maior influência antrópica possuem maior grau de poluição em relação às bacias hidrográficas com menor grau de degradação. Nesse sentido, preservar as matas ciliares ajuda a reduzir as concentrações médias de vários solutos (EMMETT et al., 1994).

Além do assoreamento provocado pelo desmatamento e processos de canalização na área urbana (PEREIRA; ALVES, 2013) o Córrego Tamanduá sofre com o despejo de efluentes doméstico e empresarial que alteram a qualidade da água (BATISTA et al., 2017). Infelizmente não há fiscalização e interesse dos gestores em cuidar desse aspecto (PEREIRA; ALVES, 2013). Esses problemas na área urbana juntamente com os efeitos do desmatamento a montante só agravarão a situação da BT e influenciarão na qualidade de água que sai da bacia. A partir desse ponto o problema deixa de ser local, do município, e passa a ser de outras regiões que utilizarão a água à jusante da cidade de Iporá.

É importante pensar em planos de gerenciamento para a bacia hidrográfica do Córrego Tamanduá, principalmente pelo fato do mesmo sofrer influência direta 
da população iporaense. A destruição dos ambientes naturais da bacia pode acarretar sérios problemas sociais e econômicos para a região. A destruição de matas ciliares agrava a crise hídrica, pois torna as nascentes desprotegidas, escasseando a água dos lençóis subterrâneos, deixa de filtrar e frear a velocidade da água das chuvas, provocando enchentes e prejudicando a qualidade da água (VIEGAS, 2012).

A Política Nacional de Recursos Hídricos, criada através da lei 9.433 de 8/01/97 (BRASIL, 1997), institui que a água é domínio público, dotado de valor econômico e que a gestão de recursos hídricos deve sempre proporcionar o uso múltiplo das águas. Por isso, a gestão de recursos hídricos, tendo a bacia hidrográfica como unidade de planejamento, é necessária e deve ocorrer com a colaboração da comunidade, pois é preciso que todos aqueles com direito ao uso da água também participem desse gerenciamento (BERNARDI et al., 2012). Essa necessidade de se criar instâncias de negociação entre múltiplos atores em torno de problemas sobre a água e a confiança no modelo de gestão por bacias hidrográficas, em contexto ambiental, político e econômico, propicia a criação dos comitês de bacias hidrográficas (ABERS; JORGE, 2005). Esses comitês têm como atribuição legal deliberar sobre a gestão da água, de forma compartilhada com o poder público, e tem como principal decisão a aprovação do Plano de Recursos Hídricos da Bacia, que deve estar de acordo com as leis do país (BRASIL, 2011).

\section{CONSIDERAÇÕES FINAIS}

O crescimento urbano da cidade de Iporá gerou perda de habitat através do desmatamento para realizar loteamentos e construção de residências. Com isso há evidente perda de fragmentos de vegetação causada pelo processo de urbanização. Por isso o crescimento urbano deve ser devidamente planejado, considerando fatores sociais, ambientais e econômicos.

Com o avanço da urbanização é preciso que haja planejamento para evitar danos maiores e perda de habitats. A conscientização para uso da água e o incentivo para pesquisas que envolvam a qualidade da mesma também são medidas necessárias. 
Como há produtores que utilizam a água à jusante da cidade é fundamental compreender em que estado de qualidade a água está saindo da bacia hidrográfica. Além disso, é preciso trabalhar, principalmente com os agropecuaristas, a importância da manutenção da mata ciliar e de galeria.

É notável forte melhoria na região quanto à interação entre poder público e sociedade, principalmente após a recente criação do Conselho Municipal de Defesa do Meio Ambiente e da Secretaria de Meio Ambiente e Desenvolvimento Sustentável. Assim, encorajamos o fortalecimento dessa relação na região de Iporá, pois acreditamos que essas interações podem ser importantes para gestão ambiental no município.

\section{AGRADECIMENTOS}

Agradecemos à Faculdade de Iporá - FAI, por todo apoio e incentivo; Ao professor Me. Dhego Ramon dos Santos, ex-coordenador do curso Tecnologia em Gestão Ambiental da FAI, que nos ajudou e apoiou, enquanto membro da banca do trabalho que originou esse artigo; Ao nosso amigo Me. Fagner Junior Machado de Oliveira, pelas discussões e sugestões; Ao nosso grupo de estudos, à época composto por mais três acadêmicos: Guilherme Vilela Araújo de Sá, Reyner Lima Morais e Rodrigo Silva Barroso.

\section{REFERÊNCIAS}

ABERS, R.; JORGE, K. D. Descentralização da gestão da água: por que os comitês de bacias estão sendo criados?. Ambiente \& Sociedade, v. 8, n. 2, 2005.

AB'SABER, A. Os domínios de natureza no Brasil. 2. ed. São Paulo: Ateliê Editorial, 2003.

ALVARES, C. A.; STAPE, J. L.; SENTELHAS, P. C.; GONÇALVES, J. L. DE M.; SPAROVEK, G. Köppen's climate classification map for Brazil. Meteorologische Zeitschrift, v. 22, n. 6, p. 711-728, 2013. 
AZEVEDO, H. A. M. A.; BARBOSA, R. P. Gestão de recursos hídricos no Distrito Federal: uma análise da gestão dos comitês de bacia hidrográfica. Ateliê Geográfico, v. 5, n. 13, p. 162-182, 2011.

BATISTA, D. F.; CABRAL, J. B. P.; ROCHA, T.; BARBOSA, G. B. Avaliação do oxigênio dissolvido nas águas do ribeirão Paraíso em Jataí-GO e córrego Tamanduá em Iporá-GO. Caminhos de Geografia, v. 18, n. 64, p. 296-309, 2017.

BERNARDI, E. C. S.; PANZIERA, A. G.; BURIOL, G. A.; SWAROWSKY, A. Bacia hidrográfica como unidade de gestão ambiental. Disciplinarum Scientia, v. 13, n. 2, p. 159-168, 2012.

BRASIL. Lei $\mathrm{n}^{\circ}$ 9.433, de 8 de janeiro de 1997. Institui a Política Nacional de Recursos Hídricos, cria o Sistema Nacional de Gerenciamento de Recursos Hídricos. Diário Oficial [da] República Federativa do Brasil, 8 jan. 1997.

BRASIL. Fragmentação de ecossistemas: causas, efeitos sobre a biodiversidade e recomendações de políticas públicas. Brasília: MMA/SBF, 2003.

BRASIL. Agência Nacional de Águas. O Comitê de Bacia Hidrográfica: o que é e o que faz? Brasília: SAG, 2011. 64 p. ISBN 978-85-89629-76-8.

CHAVES, H. M. L.; SANTOS, L. B. Ocupação do solo, fragmentação da paisagem e qualidade da água em uma pequena bacia hidrográfica. Revista Brasileira de Engenharia Agrícola e Ambiental, v. 13, p. 922-930, 2009.

COELHO, V. H. R.; MONTENEGRO, S. M. G. L.; ALMEIDA, C. N.; LIMA, E. R. V.; RIBEIRO NETO, A.; MOURA, G. S. S. Dinâmica do uso e ocupação do solo em uma bacia hidrográfica do semiárido brasileiro. Revista Brasileira de Engenharia Agrícola e Ambiental, v. 18, n. 1, p. 64-72, 2014.

CORDEIRO, G. G.; GUEDES, N. M.; KISAKA, T. B.; NARDOTO, G. B. Avaliação rápida da integridade ecológica em riachos urbanos na bacia do rio Corumbá no Centro-Oeste do Brasil. Revista Ambiente e Água, v. 11, n. 3, 2016. DOI: 10.4136/ ambi-agua.1857. 
DONADIO, N. M. M.; GALBIATTI, J. A.; PAULA, R. C. Qualidade da água de nascentes com diferentes usos do solo na Bacia Hidrográfica do Córrego Rico, São Paulo, Brasil. Engenharia Agrícola, v. 25, p. 115-125, 2005.

EMMETT, B. A.; HUDSON, J. A.; COWARD, P. A.; REYNOLDS, B. The impact of a riparian wetland on stream water quality in a recently afforested upland catchment. Journal of Hydrology, v. 162, p. 337-353, 1994.

ETTO, T. L.; LONGO, R. M.; ARRUDA, D. R.; INVENIONI, R. Ecologia da paisagem de remanescentes florestais na bacia hidrográfica do ribeirão das pedras - Campinas-SP. Revista Árvore, v. 37, n. 6, p. 1063-1071, 2013.

FAHRIG, L. Effects of habitat fragmentation on biodiversity. Annual Review of Ecology, Evolution and Systematics, v. 34, p. 487-515, 2003. DOI: 10.1146/annurev.ecolsys.34.011802.132419.

GARCEZ, L. N.; ALVAREZ, G. A. Hidrologia. 10. ed. rev. e atual. São Paulo: Blucher, 1988. ISBN 978-85-212-0169-4.

GOIÁS (Estado). Secretaria de Indústria e Comércio. Superintendência de Geologia e Mineração. Caracterização climática do Estado de Goiás. Goiânia, 2006. p. 133.

LIMA, J. E. F. W.; SILVA, E. M. Estimativa da produção hídrica superficial do cerrado brasileiro. In: SCARIOT, A.; SOUSA-SILVA, J. C.; Felfili, J. M. (ed.). Cerrado: ecologia, biodiversidade e conservação. Brasília: Ministério do Meio Ambiente, 2005.

MCGARIGAL, K.; CUSHMAN, S. A.; ENE, E. Fragstats v4: spatial pattern analysis program for categorical and continuous maps. [s. l.]: [s. n. ], 2012.

MARMONTEL, C. V. F.; RODRIGUES, V. A. Parâmetros indicativos para qualidade da água em nascentes com diferentes coberturas de terra e conservação da vegetação ciliar. Floresta e Ambiente, v. 22, n. 2, p. 171-181, 2015. DOI: 10.1590/21798087.082014.

PEREIRA, J. M.; ALVES, W. S. Córregos em áreas urbanas: a atual situação do córrego Tamanduá em Iporá-GO. Revista Visão Acadêmica, v. 4, n. 6, p. 5-17, 2013. DOI: 10.4136/ambi-agua.1802. 
PEREIRA, B. W. F. et al. Uso da terra e degradação na qualidade da água na bacia hidrográfica do rio Peixe-Boi, PA, Brasil. Revista Ambiente e Água, v. 11, n. 2, 2016.

PIRES, J. S. R.; SANTOS, J. E.; DEL PRETTE, M. E. A utilização do conceito de bacia hidrográfica para a conservação dos recursos naturais. In: SCHIAVETTI, Alexandre; CAMARGO, Antonio F. M. (ed.). Conceitos de bacias hidrográficas: teorias e aplicações. Ilhéus: Editus, 2002. p. 261-291.

PIVELLO, V. R. Manejo de fragmentos de Cerrado: princípios para a conservação da biodiversidade. In: SCARIOT, A.; SOUSA-SILVA, J. C.; FELFILI, J. M. (ed.). Cerrado: ecologia, biodiversidade e conservação. Brasília: Ministério do Meio Ambiente, 2005. p. 439.

PORTO, M. F. A.; PORTO, L. R. Gestão de bacias hidrográficas. Estudos Avançados, v. 22, n. $63,2008$.

PRIMACK, R. B.; RODRIGUES, E. Biologia da conservação. Londrina: Editora Planta, 2001. p. 327.

ROSS, J. L. S.; DEL PRETTE, M. E. Recursos hídricos e as bacias hidrográficas: âncoras do planejamento e gestão ambiental. Revista do Departamento de Geografia, n. 12, p. 89-121, 1998.

SANTOS, E. F.; SOUSA, F. A. Aspectos morfométricos da bacia do córrego Tamanduá em Iporá-GO. Acta Geográfica, v. 7, n. 15, p. 191-199, 2013. DOI: 10.5654/ actageo2013.0715.0012.

SAUNDERS, D. A.; HOBBS, R. J.; MARGULES, C. R. Biological consequences of ecosystem fragmentation: a review. Conservation Biology, v. 5, n. 1, p. 18-32, 1991.

SAWYER, D. Índice de pressão antrópica (IPA): uma proposta metodológica. In: BRASIL. Ministério do Meio Ambiente. Biodiversidade do Cerrado e Pantanal: áreas e ações prioritárias para conservação. Brasília: MMA, 2007. p. 540.

SILVA, F. A. M.; ASSAD, E. D.; EVANGELISTA, B. A. Caracterização climática do bio- 
ma cerrado. In: SANO, S. M.; ALMEIDA, S. P.; RIBEIRO, J. F. (ed.). Cerrado: ecologia e flora. Brasília: Embrapa Informação Tecnológica, 2008. p. 69-87.

SOUZA, M. M.; GASTALDINI, M. C. C. Avaliação da qualidade da água em bacias hidrográficas com diferentes impactos antrópicos. Engenharia Sanitária Ambiental, v. 19, n. 3, p. 263-274, 2014. DOI: 10.1590/S1413-41522014019000001097.

TABARELLI, M.; GASCON, C. Lições da pesquisa sobre fragmentação: aperfeiçoando políticas e diretrizes de manejo para a conservação da biodiversidade. Megadiversidade, v. 1, n. 1, 2005.

TEODORO, V. L. I.; TEIXEIRA, D.; COSTA, D. J. L.; FULLER, B. B. O conceito de bacia hidrográfica e a importância da caracterização morfométrica para o entendimento da dinâmica ambiental local. Revista Uniara, v. 20, p. 137-156, 2007.

VIEGAS, E. C. Gestão da água e princípios ambientais. 2. ed. Caxias do Sul: Educs, 2012. ISBN 978-85-7061-639-5.

Recebido em: 05/02/2018

Aceito em: 07/02/2019 